\title{
RADICAL CHEMISTRY AT THE SONTOS SITE IN RURAL ONTARIO
}

\author{
M. C. ARIAS and D. R. HASTIE \\ Department of Chemistry and Centre for Atmospheric Chemistry, \\ York University, 4700 Keele St., North York, Ont. M3J 1P3, Canada
}

\begin{abstract}
A chemical amplifier based radical detector was used to make measurements of radical $\left(\mathrm{RO}_{x}=\mathrm{HO}_{2}+\mathrm{HO}+\mathrm{RO}+\mathrm{RO}_{2}\right)$ concentrations at a rural site in the summer of 1992 , as part of the Southern Ontario Oxidant Study (SONTOS). The average maximum daytime radical concentration was around $7 \mathrm{pptv}$, with the maximum value recorded being $23 \mathrm{pptv}$. There was no distinguishable radical signal on any of the cloudy days, whereas there was a clear diurnal variation, maximizing in the mid afternoon on sunny days. The highest radical signals were observed on days of the highest ozone, which were days that showed photochemical ozone production. The local ozone production was calculated from the radical and NO concentrations but, even in the absence of loss terms, was insufficient to explain the ozone increase at the site. This indicates that part of the measured ozone increase is due to ozone production elsewhere followed by transport to the site. Peroxyacetyl nitrate (PAN) decomposition appears to provide about $30 \%$ of the radicals measured at the site so that the contribution of PAN as a radical reservoir needs to be considered. Fluctuations in the measured parameters prevented the meaningful determination of radical concentrations from the photostationary state at the low leveis encountered.
\end{abstract}

Key word index: Radicals, tropospheric chemistry, SONTOS, rural ozone, ozone production.

\section{INTRODUCTION}

The Windsor-Quebec Corridor has been identified as the region of Canada where the highest frequency and longest duration of ozone excursions above the maximum acceptable level occur (CCME, 1991). This region houses $84 \%$ of the population of Ontario, $64 \%$ of the population of Quebec and close to half of the entire population of Canada. It also includes $40 \%$ of Canada's Class 1 agricultural land so that the impact of ozone is a major concern in this area. It has been estimated that crop losses in the Southern Ontario region alone, due to ozone concentrations above the maximum acceptable level ( $82 \mathrm{ppbv})$, are in the order of \$45M per year (MOE, 1989). As an indication of the seriousness of the problem, the Council of the Ministers of the Environment have instituted the "Management Plan for Nitrogen Oxides $\left(\mathrm{NO}_{\mathrm{x}}\right.$ ) and Volatile Organic Compounds (VOCs) Part 1", which is aimed at "fully resolving ground level ozone problems by 2005" (CCME, 1991).

Ozone is a secondary pollutant produced through the nitrogen oxide catalysed oxidation of hydrocarbons. Its lifetime in rural areas is several days, governed primarily by the rate of surface deposition. Thus to control ozone in rural areas it is important to be able to distinguish between ozone that is produced in the immediate vicinity of the site, by local photo- chemistry, and that made elsewhere and transported to the site. One way to assess the amount of local photochemistry is to look at species that are involved in ozone production but which have a short lifetime so they are not subject to significant transport. The radicals $\mathrm{HO}_{2}$ and $\mathrm{HO}$ are such species. They only have an atmospheric lifetime of a few seconds, therefore the presence of high concentrations of radicals will point to active photochemistry (Cantrell et al., 1992), whereas low concentrations coupled with high ozone concentrations will point to significant ozone adrection into the region.

The Southern Ontario Oxidant Study (SONTOS) is a multi-faceted multi-institutional study aimed at gaining a better understanding of the oxidation chemistry in the Ontario atmosphere. The first major SONTOS field study took place in the summer of 1992, and involved measurements at two sites and from an aircraft. The primary intensive site was at Hastings, Ontario, some $150 \mathrm{~km}$ northeast of Toronto, with a second site at Binbrook, $50 \mathrm{~km}$ southwest of Toronto. The aircraft made measurements upwind and downwind of the sites, performed plume studies and measured profiles above each site.

In this paper, we present the results arising from the measurement of radical concentrations, primarily peroxy radicals, at the Hastings site. Radical and other measurements are used to determine the local ozone 
production, to allow the evaluation of the relative importance of local ozone production vs the transport of photochemically produced ozone from elsewhere. Some information on the source of the radicals as well as problems with the estimation of radical concentrations from the photostationary state are presented.

\section{EXPERIMENTAL}

Site

The Hastings site is located about $150 \mathrm{~km}$ northeast of Toronto in a lightly populated farming area, see Reid $e t$ al. (1995). The nearest town is Hastings, population 1000, $5 \mathrm{~km}$ to the southwest. The nearest major town is Peterborough, approximately $40 \mathrm{~km}$ to the northwest. This site is unlike most in North America in that it is on the northern edge of the population belt, thus it is likely to receive both clean and polluted air masses. Air from the northwest quadrant will usually not have recently contacted major urban or industrial centres so will be typical of a slightly contaminated continental environment. No impact of the town of Peterborough was observed in the data. Air from the southwest may be quite heavily impacted by both Canadian and U.S. sources.

The site itself is on a hill with an average elevation above the immediately surrounding area of about $30 \mathrm{~m}$, and is about $40 \mathrm{~m}$ above the Trent river, a largely recreational waterway. The field in which the measurement trailers were located was ungrazed pasture, and the major crops in the area were hay, fodder corn and soybeans.

The study ran from 15 July to 31 August 1992 and is described in detail in Hastie et al. (1995) and Reid et al. (1995). The radical detector was operational for this entire period, but only data from August are reported here as some of the other instruments, supplying supporting data, were only running for this limited period.

\section{Instrumentation}

Radicals were measured using a radical detector based on the principle of chetrical amplification, similar to that described in Hastie et al. (1991). The radical detector is a chemical reactor in which radicals oxidize added $\mathrm{CO}$ and $\mathrm{NO}$ to $\mathrm{CO}_{2}$ and $\mathrm{NO}_{2}$. The hydrogen radicais $\left(\mathrm{H}, \mathrm{HO}\right.$ and $\mathrm{HO}_{2}$ ) enter into a chain reaction:

$$
\begin{gathered}
\mathrm{HO}_{2}+\mathrm{NO} \rightarrow \mathrm{NO}_{2}+\mathrm{OH} \\
\mathrm{HO}+\mathrm{CO} \rightarrow \mathrm{H}+\mathrm{CO}_{2} \\
\mathrm{H}+\mathrm{O}_{2}+\mathrm{M} \rightarrow \mathrm{HO}_{2}+\mathrm{M} .
\end{gathered}
$$

Since this sequence regenerates the radical and because there is always excess $\mathrm{CO}$ and $\mathrm{NO}$, the radicals cycle through these reactions producing a large number of $\mathrm{NO}_{2}$ molecules per radical entering the system. The radical concentration can be determined from the $\mathrm{NO}_{2}$ produced and a knowledge of the number of times a radical cycles through reactions (1)-(3) before being lost to a termination reaction (the chain length). Major termination reactions in this system are

$$
\begin{aligned}
\mathrm{HO}+\mathrm{NO}+\mathrm{M} & \rightarrow \mathrm{HONO}+\mathrm{M} \\
\mathrm{NO}_{2}+\mathrm{HO}_{2}+\mathrm{M} & \rightarrow \mathrm{HNO}_{4}+\mathrm{M} \\
\mathrm{HO}_{2} & \rightarrow \text { wall loss. }
\end{aligned}
$$

Organic peroxy radicals $\left(\mathrm{RO}_{2}\right)$, that are reduced by $\mathrm{NO}$, generate an $\mathrm{HO}_{2}$ radical and so are also detected:

$$
\begin{aligned}
\mathrm{RO}_{2}+\mathrm{NO} & \rightarrow \mathrm{RO}+\mathrm{NO}_{2} \\
\mathrm{RO}+\mathrm{O}_{2} & \rightarrow \mathrm{R}^{\prime} \mathrm{COR}^{\prime}+\mathrm{HO}_{2}
\end{aligned}
$$

Therefore this detector is not specific to a particular type of radical but rather measures the sum of all radicals of the type $\mathrm{HO}_{x}$ or $\mathrm{RO}_{x}$ (with the qualifications below). For the organic radicals an additional termination reaction occurs:

$$
\mathrm{RO}+\mathrm{NO}+\mathrm{M} \rightarrow \mathrm{RONO}+\mathrm{M} .
$$

This prevents the conversion of some of the organic peroxy radicals to hydroperoxy radicals through reactions ( 7$)$ and (8). For example, in the system used here, only $94 \%$ of the methyl peroxy radicals are converted, giving a chain length for these radicals $6 \%$ lower than for hydroperoxy radicals. Photochemical models for the daytime NO conditions encountered in this study ( $>150 \mathrm{pptv}$ ), show the organic radicals to be less than $20 \%$ of the total radical load (e.g. Plummer et al., 1995), so neglecting reaction (9) would induce an error of $1.2 \%$ in the total radical concentration. Thus the radical concentration is determined as the $\mathrm{NO}_{2}$ produced by the chain reaction divided by the chain length for hydroperoxy radicals.

To measure the radicals it is necessary to discriminate between the $\mathrm{NO}_{2}$ produced by the chain reaction and that from other sources. For example, there is $\mathrm{NO}_{2}$ in the ambient air sample, and $\mathrm{NO}_{2}$ is produced by the titration of ambient ozone with the NO added to the system. Discrimination against these background $\mathrm{NO}_{2}$ sources is accomplished by modulating the signal. The chemistry is turned on and off by changing the time at which $\mathrm{CO}$ is added to the reactor. When $\mathrm{CO}$ is added simultaneously with $\mathrm{NO}$ at the ambient air inlet the chain chemistry is "on" $\mathbf{N O}_{2}$ is being produced by the chain reaction). If $\mathrm{CO}$ is added downstream from the inlet, radicals are lost to reactions (4) and (6) before encountering the $\mathrm{CO}$; thus reaction (2) does not occur, and the chemistry is "off". However, the $\mathrm{NO}_{2}$ from the back ground sources is still present. Thus the $\mathrm{NO}_{2}$ produced from the chain reaction is the difference between these two measurements.

The system employed here used a total $\mathrm{CO}$ concentration of $4 \%$ and a total NO concentration of $2 \mathrm{ppmv}$. The $\mathrm{CO}$ addition point was changed from its first position (close to the inlet) to its second position $(0.9 \mathrm{~m}$ downstream) every $75 \mathrm{~s}$, so two full measurements, with backgrounds, were acquired every $5 \mathrm{~min}$. The $\mathrm{NO}_{2}$ concentration was measured using a commercial luminol based detector (LMA-3, Unisearch Associates), which was routinely calibrated against a known concentration of $\mathrm{NO}_{2}$ in air produced by diluting the output from an $\mathrm{NO}_{2}$ permeation device. The permeation tube was calibrated against a known mixture of $\mathrm{NO}_{2} \mathrm{ob}$ tained by diluting a $6 \mathrm{ppmv}$ standard of $\mathrm{NO}$ in $\mathrm{N}_{2}$ (Scott Spociality gases Certified Standard) with synthetic air and passing the mixture through a chromium trioxide converter which quantitatively converts the $\mathrm{NO}$ to $\mathrm{NO}_{2}$ (Drummond et al., 1989). Since the detector is not linear for $\mathrm{NO}_{2}$ concentrations below $\sim 3$ ppbv (Drummond et al., 1989), a flow of NO from a second permeation device was continuously added to the air stream just prior to detection. This ensured a minimum $\mathrm{NO}_{2}$ concentration of $10 \mathrm{ppbv}$, well above the nonlinear regime of the detector. All instrument functions and the data collection were controlled by a PC. Data were not collected for 15 or $20 \mathrm{~s}$ after each change in $\mathrm{CO}$ addition, to allow flows to stabilize. The output from the detector was measured at $2 \mathrm{~Hz}$ and averaged for the remainder of the $75 \mathrm{~s}$ interval.

The system was calibrated for radicals using peroxyacetyl radicals obtained from the thermal decomposition of gas phase PAN (Hastie et al., 1991). A solution of PAN in dodecane was produced by the method of Nielsen et al. (1982) and purified as described in Blanchard et al. (1990). Gas phase PAN was produced by bubbling $\mathrm{N}_{2}$ through this solution, and its concentration determined using a Gas
Chromatograph with an Electron Capture Detector (BlancChromatograph with an Electron Capture Detector (Blanc-
hard et al., 1990). The gas phase PAN flow was then diluted

(8) in zero air as required for calibration. To decompose the 
PAN for calibration, a $30 \mathrm{~cm}$ section of the inlet was constructed of $1 / 4^{\prime \prime}$ diameter quartz tubing which could be heated to $300^{\circ} \mathrm{C}$ as required. Heating air in the absence of PAN produced a small signal which amounted to $\sim 6-8 \%$ of that in the presence of PAN. This was subtracted from the calibration signal. Multiple calibrations in the laboratory yielded a chain length of $100 \pm 35$, where the error includes the standard deviation of the multiple determinations and the error in the PAN calibration. The system was calibrated in a similar manner during the field campaign, except that the PAN concentration was determined using a TECAN NO analyser equipped with an $\mathrm{Au} / \mathrm{CO}$ reduction catalyst (Fahey et al., 1986). The field determination of the chain length was within the range of the values obtained in the laboratory.

The minimum detectable concentration (MDC) of the instrument in the laboratory is governed by the random noise in the $\mathrm{NO}_{2}$ detector. However, in the field, where a background signal of up to 100 times the radical signal must be subtracted, it is the variation in the background signal that dominates. Since each $\mathbf{3 0}$ min radical determination is composed of 12 alternating radical and background measurements, only nonlinear variations in the background signal will impact the MDC. We have examined the random noise using a laboratory zero air sample and the noise under field conditions by examining the variation in early morning data, where it is assumed that the radical concentration is zero. The instrument noise on a zero air sample in the laboratory is random and yields a $3 \sigma$ radical MDC, for a 1 min measurement, of $1.2 \mathrm{pptv}$. Extrapolating this value to the 5 min cycle, allowing for the non measurement time (20\%) and doubling the MDC, because of the subtraction, yields an MDC of 1.2 ppty. In this study the instrument data were averaged over $30 \mathrm{~min}$, so the random noise component of the MDC was $0.5 \mathrm{pptv}$. Using early morning data allows examination of both the noise due to instrument drift and the noise induced by changes in the background ozone and $\mathrm{NO}_{2}$ concentrations. Three six hour periods, from midnight to $06: 00 \mathrm{~h}$ on 5,12 , and 20 August 1992 were examined. The $30 \mathrm{~min}$ averages of the radical concentration over these peri- ods showed standard deviations of 0.4-0.9 ppty which leads to $3 \sigma$ radical MDCs of $1-2.6 \mathrm{pptv}$. This MDC increases when there are rapid changes in ozone and $\mathrm{NO}_{2}$ but, fortunately, such conditions are associated with rapidly changing air masses which are generally of little interest, therefore an average MDC of 2 ppty is applicable to this study. The measurement accuracy above this MDC is $\pm 35 \%$ as it is governed by the accuracy of the chain length determination.

Solar irradiation was measured with an upward looking u.v. radiometer (Eppley Laboratory, Inc., Newport, RI). This radiometer is sensitive to radiation from $295-385 \mathrm{~nm}$ and since the calibration was rather old and the sensitivity of these radiometers is known to drift, was used primarily as a relative measure of the solar irradiance. It was also used to estimate the rate of $\mathrm{NO}_{2}$ photolysis. A clear sky value of the photolysis rate for a particular day at the Hastings site was deduced from Madronich $e t$ al. (1983) and served to calibrate the radiometer for one solar zenith angle. The photolysis rate for a particular day was determined from the radiometer output according to the equations of Madronich (1987).

Nitric oxide and $\mathrm{NO}_{2}$ were measured by a TECAN model CLD 770-AL ppt with a PLC-760 photolytic converter. NO was also measured using a Thermoelectron model $42 S$ high sensitivity chemiluminescent analyser. Ozone measurements were made with two u.v. absorption analysers, a Dasibi model 1003-AH and a Thermoclectron Model 49. These units were calibrated by the Ontario Ministry of the Environment's audit group, before and during the study, and found to be within $6 \%$ of the NBS traceable standard. Details of these instruments and their use in this study can be found in Hastie et al. (1995).

\section{RESULTS AND DISCUSSION}

\section{Radical measurements}

Figure 1 shows the time series of the $30 \mathrm{~min}$ averaged $\mathrm{RO}_{x}$ measurements for the month of August.

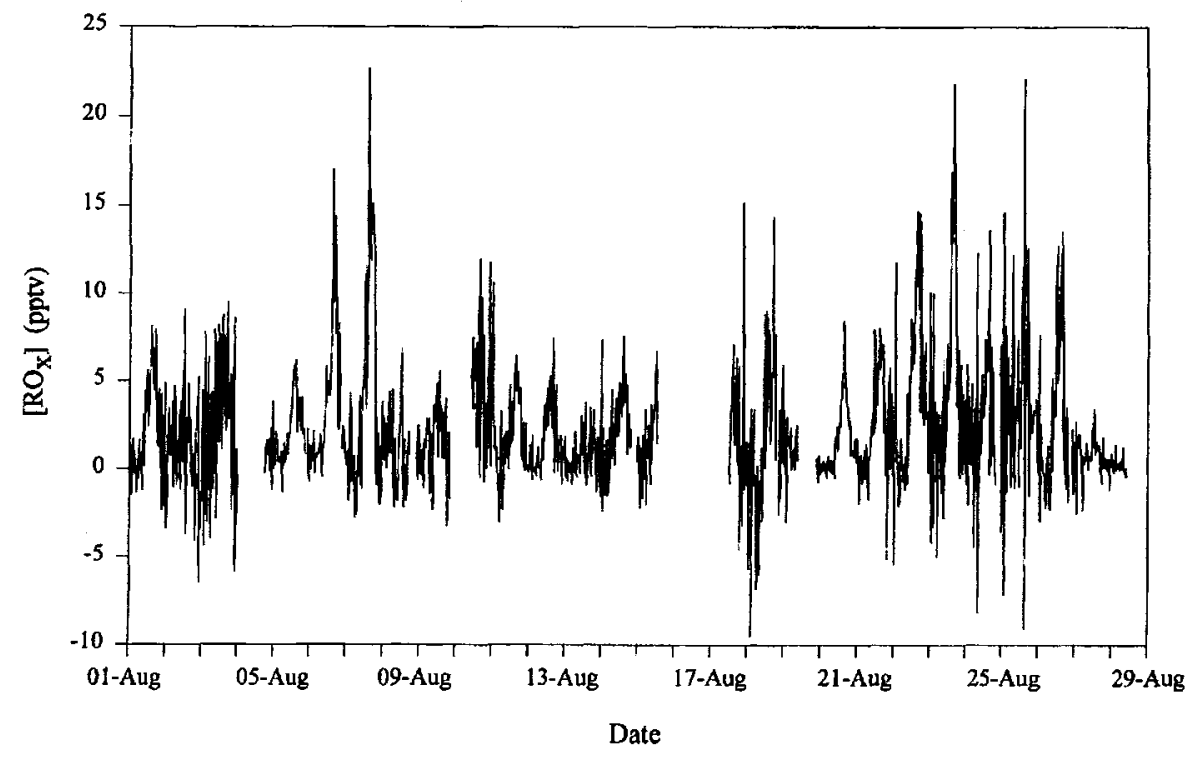

Fig. 1. The radical concentration measured, at Hastings Ontario, for the month of August 1992. 


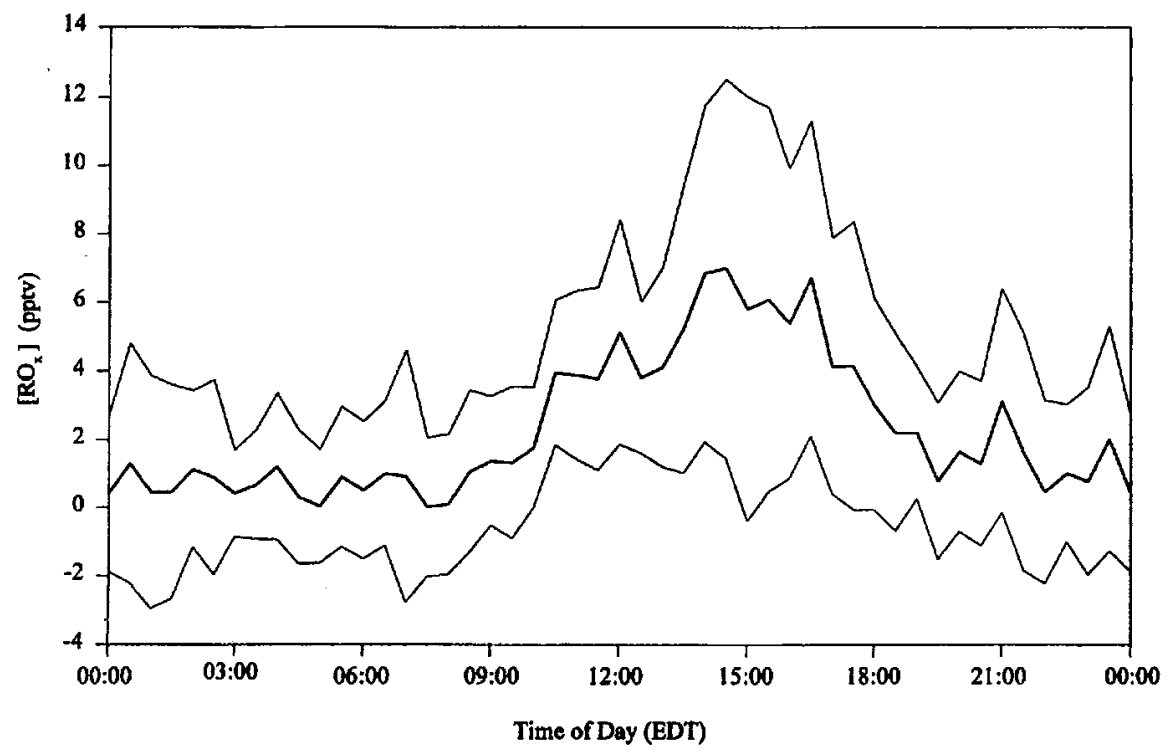

Fig. 2. The average diurnal radical concentration for the month of August 1992. The lighter lines represent the mean \pm one standard deviation.

The concentrations show a diurnal variation, but are generally low only exceeding 15 pptv on five of the 28 days sampled. The maximum concentration measured during the study was $23 \mathrm{pptv}$. The highest concentrations of radicals were observed on the days of highest ozone concentrations. Figure 2 presents the average diurnal variation in the radical concentration obtained by averaging all the data in Fig. 1 . There is a clear diurnal trend, with a concentration minimum at night and maximum at mid-afternoon. The concentration maximum occurs at $\approx 14: 30 \mathrm{~h}$ which is displaced a little over one hour with respect to overhead sun, which occurs at Hastings at $13: 12 \mathrm{~h}$. After 22:00 h the $\mathrm{RO}_{x}$ signal is below the detection limit of the instrument, so there is no evidence for radicals being measured throughout the night. These concentrations are almost a factor of three lower than predicted by the 1D model used to interpret the behaviour of the longer-lived species (Plummer et al., 1995). This suggests that either the radical measurements are underestimating the actual concentrations, or that the model is overestimating radical production, or omitting significant radical removal processes.

Figure 3 shows the average radical concentrations in the same manner as Fig. 2 but the data have been divided into sunny (19) and cloudy (5) days on the basis of the solar-radiation measurements. The averaged ozone concentrations are also shown. Both the radical and ozone concentrations are higher, and exhibit a stronger diurnal variation, on the sunny days
(Fig. 3, upper) in contrast to the cloudy days (Fig. 3, lower). Also there is an indication of a radical signal persisting after sunset until about $22: 00 \mathrm{~h}$. This suggests a non-zero nighttime radical concentration, however, this suggestion must be treated with caution as the signal is at the detection limit of the instrument. The data from the sunny days were further divided into days with high and low ozone concentrations. A high-ozone-concentration day is defined as one where the ozone concentration exceeded $50 \mathrm{ppbv}$ between 10:00 and 18:00 h, and all other days are considered as low-ozone days. Figure 4 shows the radical and ozone data divided in this way. There is a higher radical concentration in the presence of higher ozone with the average reaching $10 \mathrm{pptv}$. This could be an indication of active photochemistry at the site, with radicals acting as initiators of ozone production. However, the radical concentration consistently peaks some $3 \mathrm{~h}$ before the ozone maximum. In fact, the time of the ozone maximum is determined by the onset of the nocturnal boundary layer (Hastie et al., 1995). This suggests that, although it appears to be photochemically produced, the observed ozone increase is not strongly related to the local radical concentration.

\section{Local ozone production}

The previous section has shown that although there is a relation between the radical concentration and high ozone concentration it is by no means unequivocal. The data presented here can be used to estimate 

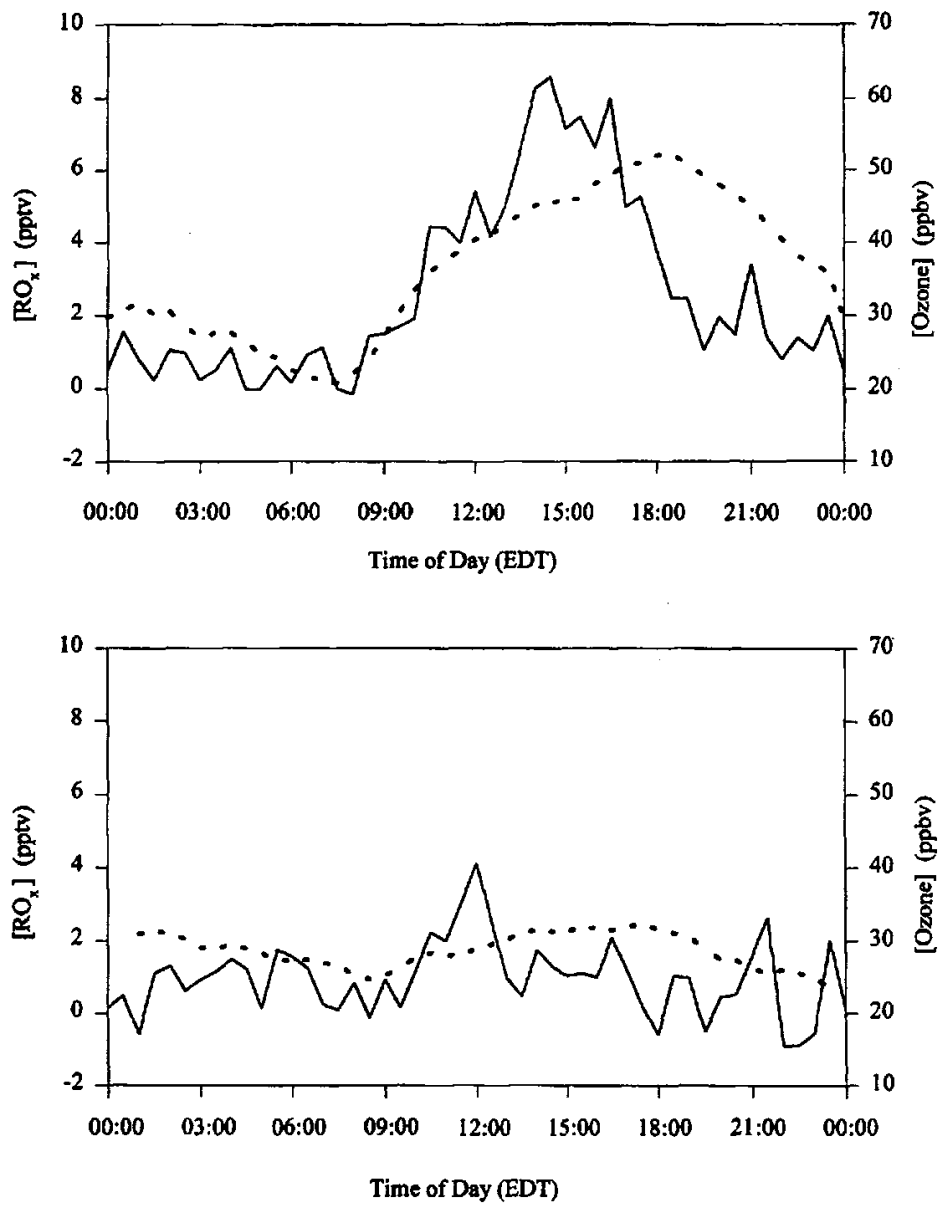

Fig. 3. The average diurnal radical (solid lines) and ozone concentrations (dotted lines) for sunny (upper) and cloudy (lower) days.

the rate of local ozone production for comparison with the observed ozone increase.

The net ozone increase can be estimated from the diurnal ozone profile. The average ozone concentration for the month of August is shown, along with those of $\mathrm{NO}$ and $\mathrm{NO}_{2}$, in Fig. 5. There is a clear diurnal trend in all concentrations. For ozone there is a concentration maximum in the late afternoon $(\approx 18: 00 \mathrm{~h})$ and minimum in the early morning $(\approx 07: 00 \mathrm{~h}$ ). Shortly after $18: 00 \mathrm{~h}$, the ozone concentration starts to decay under the nocturnal inversion due to surface deposition and possibly reaction with fresh NO emissions, until it reaches its early morning minimum. The rapid increase in concentration after $08: 00 \mathrm{~h}$ is due to the break up of the nocturnal inversion layer bringing undepleted air from aloft. By $10: 30 \mathrm{~h}$ the boundary layer is well mixed so the steady increase from this time to $18: 00 \mathrm{~h}$ is due to a combination of horizontal advection and photochemical production.

The local photochemical ozone production can be determined if we assume that the nitrogen chemistry at the site is controlled by the following reactions:

$$
\begin{aligned}
\mathrm{NO}+\mathrm{O}_{3} & \rightarrow \mathrm{NO}_{2}+\mathrm{O}_{2} \\
\mathrm{NO}_{2}+\mathrm{h} v & \rightarrow \mathrm{NO}+\mathrm{O} \\
\mathrm{O}+\mathrm{O}_{2}+\mathrm{M} & \rightarrow \mathrm{O}_{3}+\mathrm{M} \\
\mathrm{RO}_{2}+\mathrm{NO} & \rightarrow \mathrm{NO}_{2}+\mathrm{RO}
\end{aligned}
$$

and that the nitrogen species are in steady state. The ozone production rate, at the location of the measurements, can be calculated using the expression

$$
\mathrm{d}\left[\mathrm{O}_{3}\right] / \mathrm{d} t=k_{12}\left[\mathrm{RO}_{2}\right][\mathrm{NO}]
$$



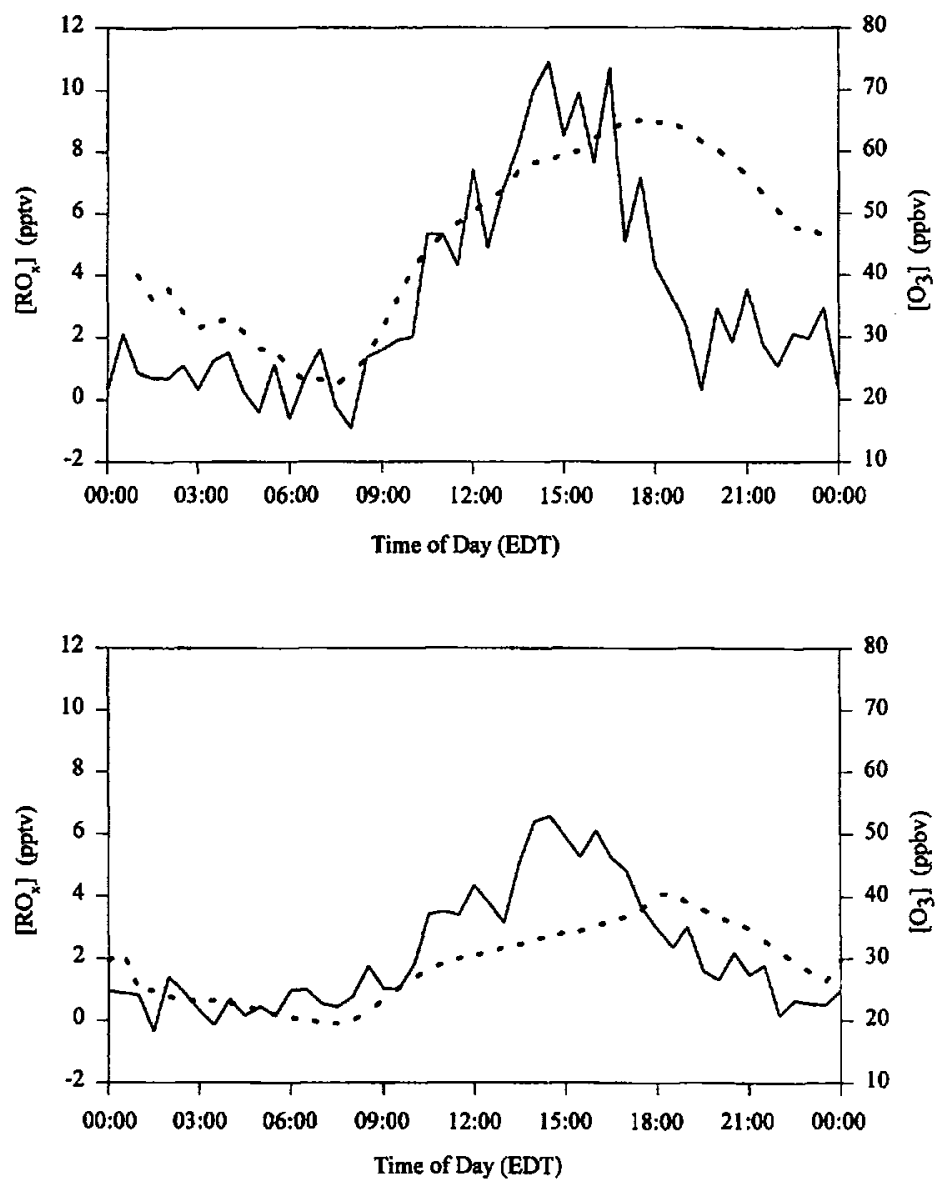

Fig. 4. The same as Fig. 3, but for sunny days of high-ozone (upper) and for sunny yet low-ozone days (lower). A high-ozone day is defined as one where the ozone concentration exceeded 50 ppbv between 10:00 and 18:00 h, all other days are considered as low-ozone days.

The detector measures all radicals but models indicate that the peroxy radicals dominate over alkoxy and $\mathrm{HO}$ radicals, and that of these $\mathrm{HO}_{2}$ is the most abundant. Therefore, it is reasonable to use the measured radical concentrations for $\mathrm{RO}_{2}$ and the rate coefficient for the reaction of $\mathrm{HO}_{2}$ and NO for $k_{12}$ in equation (13).

The ozone production rate was calculated from the average NO and radical concentrations over the period 10:30-18:00 $\mathrm{h}$. The average ozone-production rate during this period is $0.75 \mathrm{ppbv} / \mathrm{h}$ maximizing with the radical concentration at about $14: 30 \mathrm{~h}$. However, the observed ozone increase is approximately $1.7 \mathrm{ppbv} / \mathrm{h}$, so only $45 \%$ of the ozone increase can be attributed to local ozone production.

The same analysis has been performed for each of the sunny days where there are slightly higher radical concentrations. In 17 of the 19 sunny days, the calculated ozone-production rate could only explain between $14-84 \%$ of the observed ozone increase similar to what is observed in the average case. On the other two days, there was little evidence for photochemical production and so this analysis overestimated the observed ozone increase by between $134 \%$ and $260 \%$.

Further dividing the days into high- and low-ozone days as described above yielded no additional information. Of the nine "high" ozone days, the calculated ozone-production rate of eight of them were within $14-84 \%$ of the ozone increase seen for the sunny days. For the low-ozone days nine of the ten were in this category. Thus, there is no systematic difference in this analysis based on the amount of ozone produced. 


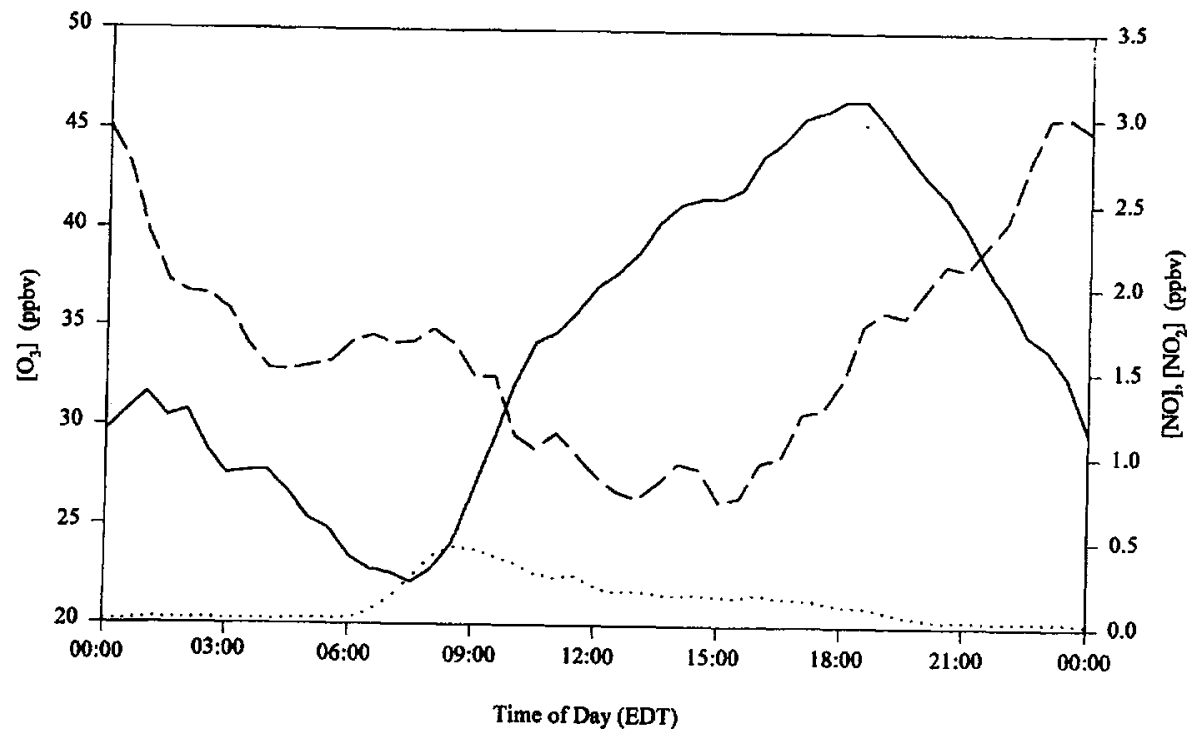

Fig. 5 The average diurnal NO (dotted line), $\mathrm{NO}_{2}$ (dashed line) and ozone (solid line) concentrations for August 1992

In the majority of cases where there was an increase in ozone in the afternoon, the calculated ozone-production rate could not explain the rate of ozone increase. Furthermore, the ozone production rate calculated in this manner should overestimate the real increase, since no deposition or reactive losses are included. Therefore, it appears as if $16-86 \%$ of the ozone increase at the site after $10: 30 \mathrm{~h}$ is due to horizontal advection. This does not preclude photochemical production of this ozone prior to advection. The continual increase in the ozone concentration suggests photochemical production upwind of the site, earlier in the day, where the precursor concentrations and solar radiation could be higher, followed by advection to the site. This is consistent with the maximum in the ozone concentration occurring at $\sim 18: 00 \mathrm{~h}$, over $3 \mathrm{~h}$ after the maximum local production rate. Furthermore at the time of the concentration maximum the ozone production rate is only $25 \%$ of its maximum value.

\section{Radical production from $P A N$}

PAN was found to be a significant fraction of the total NO, in this study (Hastie et al., 1995). As it has a lifetime with respect to thermal decomposition of about $40 \mathrm{~min}$ at this location, its decomposition may well be a significant source of radicals. The concentration of peroxyacetyl (PA) radicals can be estimated from the PAN production and destruction,

$$
\mathrm{CH}_{3} \mathrm{C}(\mathrm{O}) \mathrm{OONO} \mathrm{N}_{2} \rightleftarrows \mathrm{CH}_{3} \mathrm{C}(\mathrm{O}) \mathrm{OO}+\mathrm{NO}_{2}
$$

provided the steady-state radical concentration is achieved rapidly. The lifetime of the PA radical based on the reverse rate of equation (14) ranges from 16 to $30 \mathrm{~s}$ for the daytime $\mathrm{NO}_{2}$ concentrations encountered in this study. Numerically solving the forward and reverse rate expressions for an initial measured PAN and $\mathrm{NO}_{2}$ gives the same range of times for the $\mathrm{PA}$ concentration to reach $67 \%$ of the steady-state value. Thus the use of the simple steady-state expression

$$
[\mathrm{PA}]=\frac{k_{\mathrm{f}}[\mathrm{PAN}]}{k_{\mathrm{r}}\left[\mathrm{NO}_{2}\right]}
$$

where $k_{\mathrm{f}}$ and $k_{\mathrm{r}}$ are the forward and reverse rate coefficients for reaction (14), is justified. The PA radical concentration was calculated from the rate coefficients determined for the ambient temperature and the measured $\mathrm{NO}_{2}$ and PAN (P. B. Shepson, private communication) concentrations. Figure 6 shows the contribution of the peroxyacetyl radical to the total radical concentration measured by the radical detector. These data are for sunny days only and are further broken down into all data, where the radical concentration was above the detection limit, and for the high- and low-ozone days as defined above. On average, the peroxyacetyl radicals contribute $(30 \pm 11) \%$ to the total radical load, with higher averages for the high ozone days $(36 \pm 11) \%$ than for the low ozone days $(22 \pm 9) \%$. This shows that PAN is a significant source of radicals at the site and that local chemistry is being driven to some extent by radicals transported within the radical reservoir PAN. 


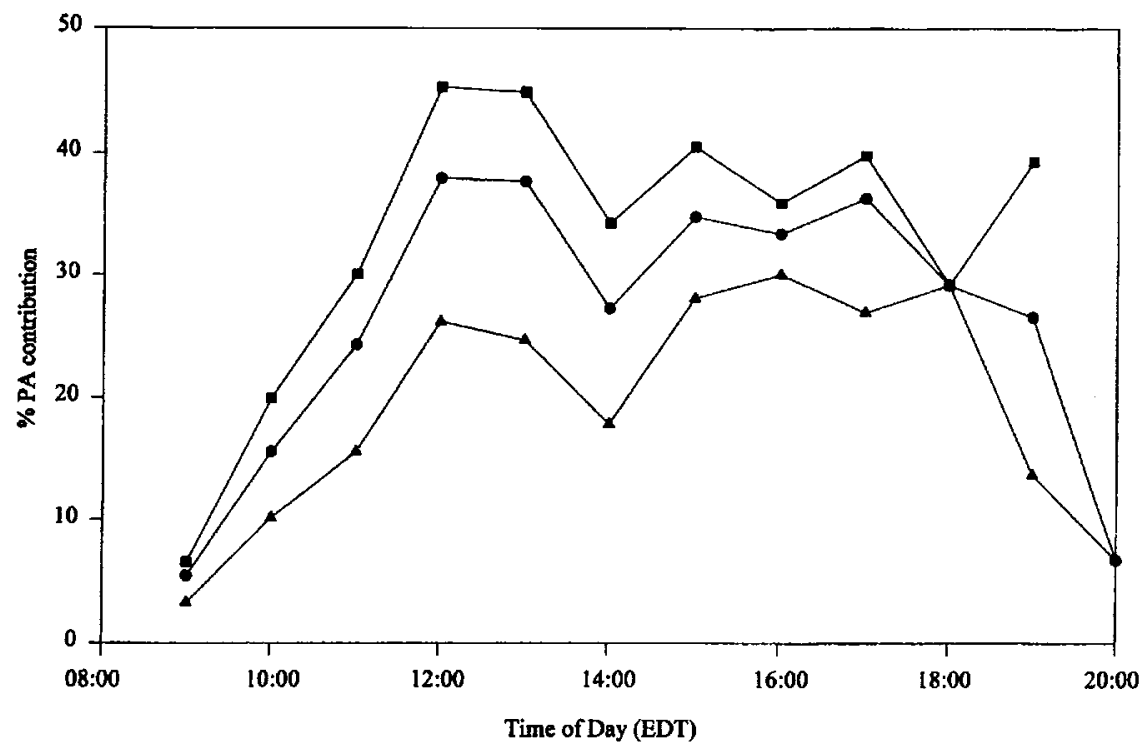

Fig. 6 The ratio of the estimated peroxy radical, obtained from the PAN and $\mathrm{NO}_{2}$ measurements, to the total radical concentration as measured by the radical detector. Results are for sunny days only (RO $\mathrm{RO}_{x}$ concentration above detection limit) (solid circles), with these days being further divided into high (solid squares) and low (solid triangles) ozone days.

It should be noted that these results are not in agreement with simple model calculations. The 1D model used to interpret the data obtained in this study (Plummer et al., 1995) obtains reasonable agreement with observed $\mathrm{NO}_{2}$ and PAN concentrations and so the PA radical concentration is within $20 \%$ of that calculated. However, the overestimation of the total radical concentration results in a model predicted PA/RO $x$ ratio of only $\sim 5 \%$ whereas the measurements indicate a ratio of $\sim 30 \%$.

Comparisons with the determination of radical concentrations using deviations from photostationary state

If reactions (9)-(12) above are controlling the nitrogen chemistry at the site then assuming that $\mathrm{NO}$ is in steady state and recognizing that $k_{10}$ is $J_{\mathrm{NO}_{2}}$, the $\mathrm{RO}_{2}$ radical concentration can be shown to be given by (e.g. Parrish et al., 1986)

$$
\left[\mathrm{RO}_{2}\right]=\frac{1}{k_{12}}\left(\frac{\mathrm{JNO}_{2}\left[\mathrm{NO}_{2}\right]}{[\mathrm{NO}]}-k_{9}\left[\mathrm{O}_{3}\right]\right)
$$

where the $k s$ are the rate coefficients for the numbered reactions. The peroxy radical concentration was determined, for the sunny days, from the measured NO, $\mathrm{NO}_{2}$ and ozone concentrations and the rate coefficients for reactions (9) and (12). The $\mathrm{NO}_{2}$ photolysis rate was determined from the Eppley radiometer as described above. The calculated radical concentrations showed a very large scatter. For example, for high ozone days they ranged from -114 to $187 \mathrm{pptv}$, with a mean of 28 pptv and a standard deviation of $74 \mathrm{pptv}$. Furthermore, the calculated radical concentrations showed no systematic diurnal pattern. The failure to obtain meaningful radical estimates is primarily due to the small difference between the terms in brackets in equation (16). Small fluctuations in the measured parameters give very large fluctuations in the determined radical concentration. Thus, under the conditions of this study the determination of the radical concentration from the steady state expression is not possible and so more direct methods of radical concentration determination must be used.

\section{CONCLUSIONS}

Radical concentration measurements have been made at a rural site in Ontario during the month of August 1992. Concentrations are almost a factor of three lower than predicted by a 1D model. This suggests that either the radical measurements are underestimated or that the model is overestimating radical concentrations. These data and the NO concentration have been used to calculate a local ozone production rate for comparison with the measured ozone increase. The calculated ozone production rate (in 20 out of 24 days) can only explain between $14 \%$ and $84 \%$ of the observed ozone increase. This suggests that daytime ozone is being produced elsewhere and it 
is being transported to the site. This agrees with the ozone maximum occurring later in the day than the radical maximum. Fluctuations in the measured parameters prevented the meaningful determination of radical concentrations from the photostationary state at the low concentrations encountered. A significan fraction of the radicals, $\sim 30 \%$, is supplied by PAN so in this environment PAN must be considered as a significant radical as well as $\mathrm{NO}_{x}$ reservoir.

Acknowledgements-We gratefully acknowledge the support of the Atmospheric Environment Service of Environment Canada for the instrumentation and the Ontario Ministry of the Environment and Energy, for field support. Helpful discussions with P. B. Shepson, J. Bottenheim and N. Reid and field support by $W$. Moroz are also acknowledged. This is Publication \# 94/9 of the Canadian Institute for Research in Atmospheric Chemistry.

\section{REFERENCES}

Blanchard P., Shepson P. B., So K. W., Schiff H. I., Bottenheim J. W., Gallant A. J., Drummond J. W. and Wong P. (1990) A comparison of calibration and measurement techniques for gas chromatographic detection of atmospheric peroxyacetyl nitrate (PAN). Atmospheric Environment 24A, 2839-2846.

Cantrell C. A., Lind J. A., Shetter R. E., Calvert J. G., Goldan, P. D., Kuster W., Fehsenfeld F. C., Montzk S. A Parrish D. D., Williams E. J., Buhr M. P., Westberg H. H. Allwine G. and Martin R. (1992) Peroxy radicals in the ROSE experiment: measurement and theory. $J$. geophys. Res. 97, 20,671-20,686

CCME (1991) Canadian Council of Ministers of the Environment. Federal/Provincial LRTAP Steering Committee Management Plan for Nitrogen Oxides $\left(\mathrm{NO}_{x}\right)$ and Volatile Organic Compounds (VOCs)

Drummond J. W., Castledine C., Green J., Denno R Mackay G. I. and Schiff H. I. (1989) New technologies for use in acid deposition networks. In Monitoring Methods for Toxics in the Atmosphere ASTM STP 1052 (edited by Zielinski W. L.) American Society for Testing and Materials, Philadelphia, Pennsylvania.

Fahey D. W. Eubank C. S. Hübler G. and Fehsenfeld F. C (1986) Evaluation of a catalytic reduction technique for the measurement of total reactive odd-nitrogen $\mathrm{NO}_{y}$ in the atmosphere. J. atmos. Chem. 3, 435-468.

Hastie D. $R$ Weissenmayer $M$. Burrows J. $P$ and Harris $G$ W. (1991) A calibrated chemical amplifier for atmospheric $\mathbf{R O}_{x}$ measurements. Analyt. Chem. 63, 2048-2057.

Hastie D. R., Shepson P. B., Reid N., Roussel R. and Melo O. T. (1995) Summertime $\mathrm{NO}_{x}, \mathrm{NO}_{y}$, and ozone at a site in rural Ontario Atmospheric Enviromment 30, 2157-2165.

Madronich S. (1987) Intercomparison of $\mathrm{NO}_{2}$ photodissociation and u.v. radiometer measurements. Atmospheric Environment 21, 569-578.

Madronich S., Hastie D. R., Ridley B. A. and Schiff H. I. (1983) Measurement of the photodissociation coefficient of $\mathrm{NO}_{2}$ in the atmosphere: $I$. Method and surface measurements. J. atmos. Chem. 1, 3-25.

MOE (1989) Ministry of the Environment. Impact of Ozone Exposure on Vegetation in Ontario.

Nielsen T., Hansen A. M. and Thomsen E. L. (1982) A convenient method for the preparation of pure standards of peroxyacetyl nitrate for atmospheric analyses. Atmospheric Environment 16, 2447-2450.

Parrish D. D., Trainer M, Williams E J, Fahey D. W, Hübler G, Eubank C. S., Liu S. C., Murphy P. C., Albritton D. L. and Fehsenfeld F. C. (1986) Measurement of the $\mathrm{NO}_{x}-\mathrm{O}_{3}$ photostationary state at Niwot Ridge, Colorado. J. geophys. Res. 91, 5361-5370.

Plummer D. McConnell J. C. Shepson P. B., Hastic D. R. and Niki H. (1995) Modelling of ozone formation at a rural site in Southern Ontario. Atmospheric Environment 30, 2195-2217.

Reid N. W., Niki H., Hastie D. R., Shepson P. B., Roussel P B Melo O. I. Mackay G. I. Drummond J, Schiff H. I, Poissant L. and Moroz W. (1995) The Southern Ontatio Oxidant Study (SONTOS): overview and case studies for 1992. Atmospheric Environment 30, 2125-2132 